\title{
Innovation of 5A Talent Development System's Efficient Business Strategy
}

\author{
Yanfei Gao ${ }^{1, a^{*}}$ and Dayong Wang ${ }^{2}$ \\ ${ }^{1}$ Tianjin University, Tianjin, China \\ ${ }^{2}$ China United Network Communications Corp Hainan Branch, Hainan, China \\ a1060138576@qq.com \\ *The corresponding author
}

Keywords: 5A; Talent development system; Business strategy

\begin{abstract}
In the 21st century, the role of intellectual capital in economic growth is increasing, the depreciation rate of knowledge is getting higher and higher, and human capital is accelerating. The competitive advantage of traditional enterprises is such as capital advantage, scale economy and so on. Have become short, as the owner of knowledge and skills, is the enterprise to create an exclusive, heterogeneous basis. Therefore, in essence, the core competition between enterprises is the talent competition.
\end{abstract}

\section{Results Background}

According to authoritative research data from the training market, more than $70 \%$ of domestic enterprises expect their corporate universities / training centers to undertake the interpretation and implementation of talent strategy, rather than just training programs and implementers. The gap that this role is looking for is a higher challenge to the training of the firm. We need to shift our attention from the construction of the training system to the learning and development system of talent. It is not just a course that is rich in lectures. Plan, but to provide a set of business strategy and talent development based on the solution, to guide employees to learn into the work, to create a complete talent development system and learning organization.

\section{On the Universality of Domestic Enterprise Training}

Objective Factors, Affecting the Level of Learning Organization Construction Level.

Low level of economic development

The constraints of traditional thinking

Management experience and theoretical basis of the constraints

Staff quality constraints

The use of modern information technology constraints

Subjective Understanding of Bias, Resulting in Learning Organization Construction

\section{Faltering}

Understanding of the concept of learning-oriented enterprises superficial

To corporate training as a learning enterprise to build the goal

Anxious, expect too high

\section{The Current Situation of Enterprise Training and Learning Management in a Province}

Since 2008, a province operator to the overall development strategy as the guide, to enhance the capacity of staff positions for the purpose of science to establish a "set with the strategic development of enterprises to match the human resources management system" - "5A training system" As a guide to the training of the general program.

Based on the evaluation and analysis of the learning value chain, through the electronic questionnaires, the key positions of staff interviews and seminars etc., we observed that the current 
company in the training and development of the applicability and applicability of the urgent need to strengthen and enhance the main performance In: the response to the business is not enough, the application of learning is insufficient, learning feedback mechanism to be improved.

After careful study and discussion, a province operator human resources department, a branch of a college to optimize the innovation " $5 \mathrm{~A}$ " learning development system of strategic choice direction: focus on the ability of staff to enhance the system, the establishment of learning - development of maps, innovation "structured On-the-job training "and" structured informal learning "model, to build efficient personnel and organizational development system.

\section{Project Connotation and Innovation}

Project Connotation. The success of the enterprise, to a certain extent, follow the "corporate strategy x organizational capacity" of the formula. A province of operators to create a talent innovation based on the enterprise strategy of personnel development system to 5A training system as the basis, to excellence in personnel training project as the main line, around the development of learning content system, system, development system and platform system, through the construction of learning - Development of the map, with the "structured on-the-job training" and "structured informal learning" three-dimensional complementary system to promote the development of talent system, organizational capacity and corporate strategy to upgrade the floor.

The development of learning system construction: from the international perspective and support enterprise human resources strategic thinking of constructing enterprise talent learning and development system, starting from the content system, learning system, learning system and learning platform system, develop talent and organization development learning development map.

"Structured on-the-job training": the full specification of tutoring and learning content, on-the-job training in post mentors and guidance, through combing the "post task list" and "standard work", unified on-the-job training and the knowledge point and point of operation; through on-the-job guidance method standard "and" teacher ability standard ". Ensure the tutor team qualification level; through the development of the" job guidance manual "and" regular assessment "and other tools, operation process and mechanism for on-the-job training.

"Structured informal learning: informal learning time and place, with a clear learning objectives learning plan through systematic instructional design, with a fixed learning framework and tools, through social contacts and other forms of transfer and penetration of knowledge and skills, promote a learning style learners to enhance the ability of the. It is an important part of learning maps, using multiple channels to enrich learning projects, unified planning, monitoring the development path of learning staff, and effectively promote the improvement of employee performance.

Major Innovation. A province of operators to focus on promoting the organization to enhance the ability to enhance business strategy and landing "5A talent learning and development system", the main innovation in the following aspects:

(1) The first from the "learning map" to "development map" change the new concept of talent development system.

Traditional enterprise training "pays attention to the training process", pays attention to the talented person development enterprise "to pay attention to the study map, the attention development result". Learning map as employee learning development is more and more outstanding enterprise navigator, the identification and application. But learning map itself needs constant evolution and development, among them, the first dimension is the evolution of "ease of use", which uses embedded learning, fragmentation learning, mobile learning and other means to achieve learner centered learning according to need; another evolution dimension is the "effectiveness", training means step by step from "to learn the project as the center" to "take the practice as the center", to achieve the transformation and upgrading from the map to map the development of learning.

(2) The first "structured on-the-job training" and "structured informal learning" combined with the new system. 
When the map is completed, the staff has a clear learning path and ability to develop goals. This one, "structured on-the-job training" and "structured informal learning" to be complementary, just perfect supply in place, to achieve a seamless staff from learning to development process. Practice shows that the construction of the learning map is a powerful starting point to build enterprise talent development system, the integration of formal learning and informal learning mode, the seamless combination, play their respective advantages, complement each other, to build a complete, structured, dynamic talent development solutions, a solid foundation for the construction of enterprise talent development system.

(3) For the first time to build a comprehensive, systematic and efficient personnel and organizational learning development system.

Employees to obtain professional knowledge and professional skills by directly within the system of learning activities, and develop through dynamic learning system and learning habits, the staff whether the enterprise internal development or to join the society, have a considerable competitive edge. Learning development system innovation through learning the value chain, in the assessment of learning content, learning methods, learning activities, learning motivation and learning platform and the five aspects of the implementation of the capacity requirements into the ability of employees, enhance the atmosphere and effect of learning and development, and enhance the competitiveness of the entire organization

\section{The Main Approach of the Project}

From Learning the Map to the Development of the Map, the Establishment of Targeted, Forward-looking Learning Content System. 1. To staff career planning and capacity development as the main axis, drawing targeted strong "learning map", the implementation of post qualification certification. 2. To key career experience as the core of the overall development of talent development framework, depicting the staff development activities road map.

Establish a Comprehensive, Three-dimensional, Complementary Learning System. 1. To build a structured on-the-job training system to promote learning map flowering results. 2 . To create a structured informal learning system, a strong way to promote employee performance. 3 . The establishment of learning methods, personalized operation, unified output.

Design Learning Activities, Build Learning Platform, to Create Efficient Learning and Development System. 1. With experiential learning for the leveraging of learning activities designed. 2. Build a learning platform to promote knowledge sharing.

\section{The Actual Results of the Project}

Staff's Professional Quality, Job Skills and Job Performance has been Significantly Improved. A company in 2011, the company also focused on the business, $3 \mathrm{G}$ call center, operation and maintenance, network optimization, the company has a number of people in the province of marketing staff (business, set off, grid, customer service) more than 7,000 people to implement the job skills training and certification work; , Construction, information and other professional line of talent to implement the grading certification work, as of December, nearly 5,000 people attended the job skills certification.

Start the Core Key Talent Thousands of People Training Program, the organization's Competitiveness has been Significantly Improved. Since 2011, we have made efforts to build the core talents of thousands of people. We have implemented the training mechanism of core talent segment management and classification management, and adopted the combination training mode such as "research and curriculum training + cross-border study and case study".

(From the professional series of employees 6-12 level selection), reserve personnel (from the professional staff, the provincial staff manager, the city branch manager and the same level of personnel selection), the backbone of talent (from the professional series of employees 6-12 level selection), reserve talent (from the professional staff, Low-level professional series of employees in 
the following five selection), gold team (focus on selection and training set of industry marketing, $3 \mathrm{G}$ service manager, grid, business team in the top $10 \%$ of the talent).

Integration of Resources to Carry out School-Enterprise Cooperation, to Achieve the Maximum Learning Resources. To promote the "talent rise, quality optimization", a province operators since 2010 to carry out various types of enterprise cooperation projects, continuing to carry out staff education and skills upgrading, and the level of education as a necessary condition for career development, to promote the talent Knowledge structure and the overall quality of the upgrade.

Learning Innovation System, Greatly Enhance the Efficiency of the Organization, Deepen the Promotion of the Company's Business Sustained and Healthy Development. Through the innovation learning and development system, a province of operators per capita labor productivity has been significantly improved. Statistics show that a province of operators per capita labor productivity, from 2014 to 2016, from the year's 629,000 yuan per capita to 100 million, the average profitability gains per capita lead.

Market data from a group of operators at the headquarters of the province also show that the total profit of a province's operators contributed 19\% of the total amount of 31 provinces. 2012 in a province's industry revenue margins overall decline in the case, a province operator revenue margins rose 5.3 percentage points year on year. 2015and 2016per capita profit increase in more than $100 \%$.

The innovation and change of the enterprise learning and development system of a province's operators adapt to the new competitive environment, and how can the enterprises realize the strategic landing and sustainable development needs based on the long-term development of talents. Through the innovation of enterprise learning and development system, a province of operators will be the future of passive learning into active learning, from the original "training" to upgrade to "development", effectively enhance the quality of personnel, changed the talent structure, and actively promoted Enterprise learning organization construction, for enterprises to create a good economic and social benefits.

\section{References}

[1] Chen Xiaoping. The development strategy model of China talent construction of [M]. and countermeasure study of Beijing China: empirical work Mobile press( 2012 ).

[2] Wang Zhitian, Han Jinyuan, and. Discussion on the mode of talent development strategy [J]. China Science and technology Altar, 3, (2003)

[3] Shen Ronghua. The eight strategic thinking of future talent development strategy [J] Hair, 2008 (7)

[4] Wang Xiaocun ELISE survey of foreign language use and its implications for Chinese enterprises. Journal of Nanjing University of Aeronautics \& Astronautics, (4) ,2003.

[5] .WTO and Chen Naifang. Cultivation of foreign language talents. Chinese higher education, (6), 2000. 